\title{
The Association between Diabetes-Related Distress and Medication Adherence in Adult Patients with Type 2 Diabetes Mellitus: A Cross-Sectional Study
}

\author{
Irene A. Kretchy $\mathbb{D}^{1},{ }^{1}$ Augustina Koduah, ${ }^{1}$ Thelma Ohene-Agyei, ${ }^{1}$ Vincent Boima, ${ }^{2}$ \\ and Bernard Appiah ${ }^{3,4}$ \\ ${ }^{1}$ Department of Pharmacy Practice and Clinical Pharmacy, School of Pharmacy, College of Health Sciences, University of Ghana, \\ P.O. Box LG 43, Legon, Ghana \\ ${ }^{2}$ Department of Medicine and Therapeutics, School of Medicine and Dentistry, College of Health Sciences, University of Ghana, \\ P.O. Box GP 4236, Accra, Ghana \\ ${ }^{3}$ Centre for Science and Health Communication, PMB M71, Ministries, Accra, Ghana \\ ${ }^{4}$ Department of Environmental and Occupational Health, School of Public Health, Texas A\&M University Health Science Center, \\ 212 Adriance Lab Rd, 1266 TAMU, College Station, Texas, USA
}

Correspondence should be addressed to Irene A. Kretchy; ikretchy@ug.edu.gh

Received 1 July 2019; Revised 31 January 2020; Accepted 14 February 2020; Published 2 March 2020

Academic Editor: Akira Sugawara

Copyright (c) 2020 Irene A. Kretchy et al. This is an open access article distributed under the Creative Commons Attribution License, which permits unrestricted use, distribution, and reproduction in any medium, provided the original work is properly cited.

\begin{abstract}
Background. Type 2 diabetes mellitus (T2DM) is a major public health problem associated with distress. T2DM can affect health outcomes and adherence to medications. Little is however known about the association between diabetes distress and medication adherence among patients with T2DM in Ghana. Objective. The objective of the present study is twofold: to estimate distress associated with T2DM and to examine its association with medication adherence. Methods. A hospital-based crosssectional study was conducted among 188 patients with T2DM recruited from a diabetes specialist outpatient clinic at the Pantang Hospital in Accra, Ghana. Data were obtained using the Problem Areas In Diabetes (PAID) scale and the Medication Adherence Report Scale. Results. The findings showed that about $44.7 \%$ of the patients showed high levels of diabetes-related distress. Poor adherence to medications was recorded in $66.5 \%$ of the patients. Patients who were highly distressed had $68 \%$ lower odds of adhering to their medications compared to those who were not (OR: 0.32, 95\% CI: 0.15-0.65). A principal component analysis revealed four areas of T2DM distress which were conceptualized as negative emotions about diabetes, dietary concerns and diabetes care, dissatisfaction with external support, and diabetes management helplessness. Conclusion. Our findings suggest that diabetes distress is a significant determinant of medication adherence behaviour in patients with T2DM. Thus, incorporating routine screening for distress into the standard diabetes care within the Ghanaian health system and having health practitioners adopt holistic approaches to diabetes management will be important context-specific interventions to improve adherence and health outcomes of people living and coping with T2DM.
\end{abstract}

\section{Introduction}

Type 2 diabetes mellitus (T2DM) is a group of metabolic diseases characterised by elevated levels of blood glucose, leading to serious damage to other organs over time [1]. It is a major cause of morbidity, disability, and mortality among populations worldwide [2], and it is associated with increasing unhealthy lifestyle such as poor dietary choices, lack of exercise, and inadequate physical activity $[3,4]$. An estimated global prevalence of T2DM for age groups $20-79$ was $8.8 \%$ in 2015 , and it is expected to increase to $10.4 \%$ of adults by 2040 [5]. A greater burden of $75 \%$ of persons with diabetes is in 
developing countries [5]. The prevalence of T2DM in Ghana is reported to be $6.46 \%$, and this is expected to rise by $2040[5,6]$.

Type 2 diabetes mellitus is associated with negative emotions such as anxiety, depression, and distress, and these emotions have been associated with poor clinical consequences including medication nonadherence [7-10] and glycemic outcomes $[8,11,12]$. Diabetes distress reflects negative feelings surrounding the disease and refers to the emotional response to the struggles, concerns, and worries associated with the broader demands of diabetes [13]. With time, diabetes distress becomes part of the diabetes experience for many patients and it is usually context-specific [14]. The distress is from the daily hassles and demands of the disease management [15], worries about poor glycemic control [16], fears about diabetic complications [16], poor support from significant others [17, 18], stigma [19], and financial difficulties [20]. When diabetes distress becomes protracted and is not identified and managed, patients experience burnout resulting in feelings of helplessness, hopelessness, and frustration with T2DM care [21-23]. Burnout may sometimes be physiologically triggered following an acute hyperglycemic crisis [24]. Patients with high diabetes-related distress are likely to demonstrate poor self-management [21].

A systematic review of studies on T2DM in sub-Saharan Africa reported a lack of studies on the psychosocial aspect of diabetes management [25]. In Ghana, despite the presence of some policy drive and programmatic responses to T2DM in particular and chronic noncommunicable diseases in general, the effect of these programmes is yet to reflect in the lives of patients [26, 27]. Similar to other sub-Saharan African countries, the psychosocial dimensions of the illness experience have been largely unexplored in Ghana [28, 29]. Previous studies on diabetes in Ghana have focused primarily on the prevalence and determinants [6,30-34]. The primary objective of the study therefore was to estimate diabetes-specific distress and assess its impact on optimising treatment and adherence to medication in patients with T2DM. Further, the study explored the dimensions of diabetes-specific distress using principal component analysis of the Problem Areas In Diabetes (PAID) scale to observe variations and emphasize patterns of distress in the patients [7]. Although the associations between diabetes distress and adherence have been assessed previously in other countries [8-12], such studies have not been done in Ghana. This has created a gap in knowledge in the context of T2DM from an Afrocentric perspective. While medications for managing T2DM in Ghana are readily available, adherence to these medications is still not optimal $[35,36]$. Thus, the information from this study will facilitate context-specific understanding of the problem from a psychosocial perspective so that culturally appropriate adherence solutions can be instituted.

\section{Methods}

2.1. Study Design. This was a hospital-based cross-sectional study of patients with T2DM who had reported for a clinical review at the outpatient clinic at the Pantang Hospital in Accra, Ghana. The facility attends to an average of 35 patients with diabetes in a week with approximately 3 new cases reporting within the week.

2.2. Participants. A total of 188 patients with T2DM (91.3\%) were part of this study from the Pantang Hospital between May and July 2017, out of the 206 eligible participants using a simple random sampling method. The minimum sample size of 105 was obtained using the formula by Cochran (1963) and the estimated prevalence of diabetes in Ghana at $6.46 \%[6]$ :

$$
n_{0}=(\text { Deff }) \frac{\left(Z_{\propto / 2}\right)^{2} p(1-p)}{e^{2}}
$$

where $n_{0}$ is the minimum sample size, $Z_{\propto / 2}$ is 1.96 at a confidence interval at $95 \%, e$ is the level of precision, $p$ is the estimated proportion of patients with T2DM, and Deff is the design effect set at 1.03 and assuming a $10 \%$ nonresponse rate.

The study participants were adult patients with T2DM aged 18 years and over. Participants with type 1 diabetes, gestational diabetes, maturity-onset diabetes of the young, or latent autoimmune diabetes in adults were excluded from the study. Participants were also excluded if they had been diagnosed of any known psychiatric disorder according to their medical records. The hospital attends to patients with mental and physical conditions, and this exclusion criterion was necessary to avoid any known mental illness from being a possible confounder.

2.3. Measures. All participants completed questions on demographic characteristics with other clinical data about blood glucose levels obtained from the patient records. Diabetes distress was assessed using the Problem Areas In Diabetes Questionnaire [37]. This is a 20-item measure describing negative emotions related to T2DM such as anger, fear, and frustration. It uses a 5-point Likert response scale from 0 representing "no problem" to 4 representing "serious problem." To obtain the total scores ranging from 0 to 100 , initial scores are multiplied by 1.25 . Higher scores indicate greater distress with T2DM. While participants with scores of 40 and above were highly distressed, very low scores of $0-10$ may be indicative of patients in denial. The measure of reliability using Cronbach's alpha for the PAID scale in this study was 0.8299 .

To estimate the level of adherence to medications, the study used the Medication Adherence Report Scale (MARS) which assesses both intentional and unintentional nonadherence to medicines [38]. Participants responded to five items (e.g., I forget to take my medicines) on a 5-point scale from "always" to "never," and a total score of 25 and more indicated better adherence to medications [38]. The MARS has been previously used for patients with T2DM in Singapore [39]. In this study, Cronbach's alpha was 0.6967.

2.4. Ethical Consideration. The study received ethical approval from the Ethical Review Committee of the Ghana Health Service with approval number GHS-ERC:130/12/17. Permission was also obtained from the Administrator of 
TABLE 1: Background and clinical characteristics of patients with T2DM receiving treatment at Pantang Hospital.

\begin{tabular}{|c|c|c|}
\hline & Frequency & Percent \\
\hline \multicolumn{3}{|l|}{ Age } \\
\hline Mean \pm SD & $59.31 \pm 11.94$ & \\
\hline$\leq 50$ & 41 & 21.81 \\
\hline $51-60$ & 62 & 32.98 \\
\hline $61+$ & 85 & 45.21 \\
\hline \multicolumn{3}{|l|}{ Sex } \\
\hline Female & 136 & 72.34 \\
\hline Male & 52 & 27.66 \\
\hline Glucose: median (LQ, UQ) & $7.8(6.4,11)$ & \\
\hline \multicolumn{3}{|l|}{ Comorbidity } \\
\hline No & 77 & 40.96 \\
\hline Yes & 111 & 59.04 \\
\hline \multicolumn{3}{|l|}{ Number of medications } \\
\hline Mean \pm SD & $2.56 \pm 1.13$ & \\
\hline One & 31 & 16.58 \\
\hline Two & 69 & 36.90 \\
\hline Three & 54 & 28.88 \\
\hline Four or more & 33 & 17.65 \\
\hline \multicolumn{3}{|l|}{ PAID score } \\
\hline Mean \pm SD & $36.03 \pm 4.28$ & \\
\hline Not highly distressed (PAID score $<40$ ) & 104 & 55.32 \\
\hline Highly distressed (PAID score $\geq 40$ ) & 84 & 44.68 \\
\hline \multicolumn{3}{|l|}{ MARS-5 score } \\
\hline Mean \pm SD & $21.23 \pm 3.64$ & \\
\hline Low medication adherence (MARS score $<25$ ) & 125 & 66.49 \\
\hline Medication adherent (MARS score of 25) & 63 & 33.51 \\
\hline
\end{tabular}

SD: standard deviation; LQ: lower quartile; UQ: upper quartile.

the Pantang Hospital to conduct the study in the facility. Informed consent was obtained from the sampled diabetic patients, and confidentiality/privacy was assured before their participation in the study.

2.5. Data Analysis. STATA version 14 was used for the data analysis. Frequencies and percentages were reported as descriptive statistics for categorical variables. Principal component analysis with varimax rotation analysis was used to explore diabetes distress from the various elements of the PAID scale. For continuous variables, means with standard deviations were reported for normally distributed data while median and interquartile ranges were reported as descriptive statistics when the normality assumption was violated. Normality assumption of continuous variables was tested with the skewness and kurtosis Shapiro-Francia tests. Chisquared and Fisher exact tests of independence were used to test for association between categorical independent variables and the outcome variables (diabetes distress and medication adherence). The Wilcoxon rank sum test was used to compare the median of glucose levels across the various categories of the outcome variables. Binary logistic regression models were used to determine the effects of the independent variables on the outcome variables. In assessing the association between the individual item responses of PAID and medication adherence, the item responses were dichotomized into patients who regarded the item as "a problem" and "not a problem" $[16,40]$. The statistical test of significance was set at $5 \%$.

\section{Results}

3.1. Patient Characteristics. Table 1 shows the background and clinical characteristics of the patients with T2DM $(n=188)$. On average, the patients were $59.3 \pm 11.9$ years old, with females constituting the majority $(72.3 \%)$. Fiftynine percent of the patients had at least one comorbidity and were prescribed a mean of $2.6 \pm 1.1$ medications for their conditions. Averagely, participants had a glucose level of less than or equal to 7.8 (IQR: 6.4-11.0).

3.2. Diabetes Distress. While the average PAID score among the patients was $36.0 \pm 4.3,44.7 \%$ (84/188) showed high levels of distress with PAID scores $\geq 40$. The chi-squared test showed significant associations between comorbidities $(p=0.049)$, glucose levels (0.006), and high distress. 
TABLE 2: Association between background and clinical characteristics and high distress in patients with T2DM receiving treatment at Pantang Hospital.

\begin{tabular}{|c|c|c|c|c|c|c|}
\hline & \multicolumn{2}{|c|}{ High distress } & \multirow{2}{*}{ Chi-square } & \multirow{2}{*}{$p$ value } & \multicolumn{2}{|c|}{$\begin{array}{l}\text { Adjusted logistic } \\
\text { regression model }\end{array}$} \\
\hline & No, $n(\%)$ & Yes, $n(\%)$ & & & Odds ratio & $p$ value \\
\hline Sex & & & 0.01 & 0.939 & & 0.485 \\
\hline Female & $75(55.15)$ & $61(44.85)$ & & & ref & \\
\hline Male & $29(55.77)$ & $23(44.23)$ & & & $0.78(0.38-1.57)$ & \\
\hline Age & & & 2.23 & 0.327 & & 0.943 \\
\hline$\leq 50$ & $20(48.78)$ & $21(51.22)$ & & & ref & \\
\hline $51-60$ & $32(51.61)$ & $30(48.39)$ & & & $0.98(0.42-2.33)$ & \\
\hline $61 \pm$ & $52(61.18)$ & $33(38.82)$ & & & $0.89(0.38-2.05)$ & \\
\hline Glucose level: median (LQ, UQ) & $7.3(6.2,10)$ & $9.2(6.7,12.5)$ & & $0.006^{* * \S}$ & $1.12(1.04-1.21)$ & $<0.001^{* * *}$ \\
\hline Number of medications & & & 4.75 & 0.191 & & 0.138 \\
\hline One & $18(58.06)$ & $13(41.94)$ & & & ref & \\
\hline Two & $31(44.93)$ & $38(55.07)$ & & & $2.35(0.92-6.03)$ & \\
\hline Three & $34(62.96)$ & $20(37.04)$ & & & $1.06(0.38-2.92)$ & \\
\hline Four or more & $20(60.61)$ & $13(39.39)$ & & & $1.38(0.44-4.30)$ & \\
\hline Comorbidity & & & 3.87 & 0.049 & & 0.130 \\
\hline No & $36(46.75)$ & $41(53.25)$ & & & ref & \\
\hline Yes & $68(61.26)$ & $43(38.74)$ & & & $0.58(0.29-1.16)$ & \\
\hline
\end{tabular}

$\%$ : row percentages; $n$ : number of observations; ${ }^{*} p<0.01,{ }^{* *} p<0.01$, and ${ }^{* * *} p<0.001$; CI: confidence interval; ref: reference category; LQ: lower quartile; UQ: upper quartile, $\S: p$ value obtained from a Wilcoxon rank sum test.

However, results from the multiple logistic regression model showed that the blood glucose level was the only significant predictor of distress $(p<0.001)$. The odds of high diabetic distress among patients with T2DM increased by $12 \%$ with every additional unit increase in the glucose level (OR: 1.12, 95\% CI: 1.04-1.21) (Table 2).

3.3. Medication Adherence. The average MARS-5 score was $21.2 \pm 3.6$, with one-third of the patients optimally adhering to their medications. The blood glucose level was not significantly associated with medication adherence, and higher levels were observed among patients with poor medication adherence compared with those who adhered completely to their medications ( 8.4 vs. $7.1, p=0.056)$.

3.4. High Diabetes Distress and Medication Adherence. The proportion of patients with T2DM who exhibited high distress had significantly lower scores on medication adherence compared with those who were not distressed (20.2 vs. 44.2, $p=0.001)$. Those with high distress had $68 \%$ lower odds of adhering to their medications compared to those who were not distressed (OR: 0.32, 95\% CI: 0.15-0.65) (Table 3). Ten out of the twenty items on diabetes distress using the PAID scale showed significant associations with medication adherence $(p<0.05)$ (Table 4$)$. These included discouragement with diabetes treatment, uncomfortable social situations, and feelings of anger, anxiety, guilt, loneliness, and burnout.

3.5. Components of Diabetes Distress. Table 5 shows the principal component analysis of four components with eigenvalues exceeding 1 , explaining $27.18 \%, 7.49 \%, 6.91 \%$, and $6.43 \%$ of the variance, respectively.
Factor 1 was conceptualized as negative emotions about diabetes consisting of thirteen variable loadings of items such as the following: "Scared about thoughts of living with diabetes" (0.643), "Depressed about thoughts of diabetes" (0.708), "Worry about the future and complications" (0.610), "Guilt and anxiety when off-track management of diabetes" (0.603), and "Diabetes taking too much of mental energy" (0.540). The second factor was noted as dietary concerns and diabetes care consisting of two variable loadings: "Feelings of deprivation regarding food and meals" (0.596) and "No clear or concrete goals for diabetes care" (0.529). Factor 3 was referred to as dissatisfaction with external support. This comprised two variable loadings: "Feeling unsatisfied with diabetes physician" (0.464) and "Friends and family not supportive" (0.596). Diabetes management helplessness was the fourth factor, constituted by two variables: "Coping with complications of diabetes" and "Feeling burned out by constant effort to manage diabetes." The two variables had 0.510 and 0.489 varimax rotational loadings, respectively.

\section{Discussions}

The present study contributes to knowledge of illness experience of patients with T2DM from a psychosocial perspective with emphasis on diabetes distress. While studies on diabetes distress have mainly been from developed countries, fewer studies have emerged from Africa [25]. This study therefore focused on patients with T2DM in a Ghanaian health context, bearing in mind the cultural influences of illness experiences on health outcomes.

In this study, patients who experienced diabetes distress tended to poorly adhere to their medications compared with 
TABLE 3: Association between background and clinical characteristics and medication adherence status of patients with T2DM receiving treatment at Pantang Hospital.

\begin{tabular}{|c|c|c|c|c|c|c|}
\hline & \multicolumn{2}{|c|}{ Adherent (MARS-5 score of 25) } & \multirow[t]{2}{*}{ Chi-square } & \multirow[t]{2}{*}{$p$ value } & \multicolumn{2}{|c|}{$\begin{array}{l}\text { Adjusted logistic } \\
\text { regression model }\end{array}$} \\
\hline & No, $n(\%)$ & Yes, $n(\%)$ & & & Odds ratio & $p$ value \\
\hline Sex & & & 0.3 & 0.587 & & 0.370 \\
\hline Female & $92(67.65)$ & $44(32.35)$ & & & ref & \\
\hline Male & $33(63.46)$ & $19(36.54)$ & & & $1.41(0.67-2.98)$ & \\
\hline Age & & & 1.19 & 0.551 & & 0.422 \\
\hline$\leq 50$ & $30(73.17)$ & $11(26.83)$ & & & ref & \\
\hline $51-60$ & $39(62.9)$ & $23(37.1)$ & & & $1.86(0.73-4.75)$ & \\
\hline $61 \pm$ & $56(65.88)$ & $29(34.12)$ & & & $1.41(0.56-3.52)$ & \\
\hline Glucose level: median (LQ, UQ) & $8.4(6.6,11.3)$ & $7.1(6.2,10.5)$ & & $0.056^{\S}$ & $0.98(0.91-1.07)$ & 0.721 \\
\hline Number of medications & & & 5.79 & 0.122 & & 0.161 \\
\hline One & $19(61.29)$ & $12(38.71)$ & & & ref & \\
\hline Two & $51(73.91)$ & $18(26.09)$ & & & $0.66(0.24-1.78)$ & \\
\hline Three & $38(70.37)$ & $16(29.63)$ & & & $0.71(0.25-2.00)$ & \\
\hline Four or more & $17(51.52)$ & $16(48.48)$ & & & $1.83(0.58-5.81)$ & \\
\hline Comorbidity & & & 0.01 & 0.951 & & 0.471 \\
\hline No & $51(66.23)$ & $26(33.77)$ & & & ref & \\
\hline Yes & $74(66.67)$ & $37(33.33)$ & & & $0.76(0.36-1.61)$ & \\
\hline High distress & & & 12.01 & $0.001^{* *}$ & & $0.002^{* *}$ \\
\hline No & $58(55.77)$ & $46(44.23)$ & & & ref & \\
\hline Yes & $67(79.76)$ & $17(20.24)$ & & & $0.32(0.15-0.65)$ & \\
\hline
\end{tabular}

\%: row percentages; $n$ : number of observations; ${ }^{*} p<0.01,{ }^{* *} p<0.01$, and ${ }^{* * *} p<0.001$; CI: confidence interval; ref: reference category; LQ: lower quartile; UQ: upper quartile; $\S: p$ value obtained from a Wilcoxon rank sum test.

those who were not distressed about their disease experience and outcome. Diabetes distress is an essential predictor of clinical outcomes in T2DM care, and it has been linked to poor self-management, treatment adherence, and blood glucose status in such patients [41].

Findings from the PCA further showed four areas of distress by patients with T2DM. These are negative emotions, dietary concerns, dissatisfaction with external support, and diabetes management helplessness. The concept of diabetes distress in this context could be suggested to mean a combination of these four areas of concern. In a related study where distress was assessed using the diabetes distress scale, a different measure from what was used in this study, PCA yielded factors that were similar to what was obtained in this study [42]. Yet in another study involving southern rural AfricanAmerican patients with T2DM, a PCA of the PAID yielded two factors: lack of confidence and negative emotional consequences [7].

Living with T2DM can negatively impact on the psychological well-being of patients. Previous studies on negative emotions with its affective correlates in T2DM have primarily focused on depression, mainly based on clinical presentations and diagnosis in the Diagnostic and Statistical Manual for Mental Disorders [43-45]. Yet, the prospective effect of negative emotions with subclinical symptoms also has clinical implications for T2DM care and adherence [46].

Emotionally negative symptoms like discouragement, anger, anxiety, guilt, and burnout have been indicated as risk factors for physical health and health-related outcomes including medication adherence $[16,47]$. This corroborates our findings from the item analysis of the PAID and adherence. Due to the chronicity of T2DM and the fact that patients with T2DM will have to manage with living with the condition for the rest of their lives, our findings suggest the need for interventions targeting positive emotions which can buffer the effects of the negative emotions. This is because positive feelings are important in chronic diabetes care and outcomes [48]. In a related study, a meaningful relationship between the levels of positive affect and adherence measures was reported [41]. Thus, support services for T2DM can address potentially harmful effects of negative feelings and emphasize benefits of positive emotionality for better health-related outcomes. Such support services could include the use of culturally relevant communication interventions including mobile phones, mass media, social media, and face-to-face approaches and social media to address emotional needs of patients with T2DM experiencing distress.

The study also showed that T2DM patients were distressed about the nature of care from their physicians and support from social relations. In addition, having uncomfortable social situations and the feeling of loneliness with T2DM were significantly associated with poor medication adherence. This finding indicates that, from the perspective of the patients, living with T2DM could be synonymous with feeling alone with poor social support from significant others, 
TABLE 4: Association between individual item responses of PAID scale and medication adherence status of patients with T2DM receiving treatment at Pantang Hospital.

\begin{tabular}{|c|c|c|c|c|c|}
\hline \multirow[t]{2}{*}{ Items } & \multirow{2}{*}{$\begin{array}{l}\text { Total } \\
n\left(\%^{\mathrm{a}}\right)\end{array}$} & \multicolumn{2}{|c|}{$\begin{array}{c}\text { Adherent (MARS-5 } \\
\text { score of 25) }\end{array}$} & \multicolumn{2}{|c|}{ Unadjusted } \\
\hline & & No, $n\left(\%^{\mathrm{b}}\right)$ & Yes, $n\left(\%^{\mathrm{b}}\right)$ & Odds ratio & $p$ value \\
\hline No clear or concrete goals for diabetes care & & & & & 0.468 \\
\hline No problem & $137(72.87)$ & $89(64.96)$ & $48(35.04)$ & ref & \\
\hline Problem & $51(27.13)$ & $36(70.59)$ & $15(29.41)$ & $0.77(0.38-1.55)$ & \\
\hline Feeling discouraged with diabetes treatment plan & & & & & $0.007^{* *}$ \\
\hline No problem & $108(57.45)$ & $63(58.33)$ & $45(41.67)$ & ref & \\
\hline Problem & $80(42.55)$ & $62(77.5)$ & $18(22.5)$ & $0.41(0.21-0.78)$ & \\
\hline Scared about thoughts of living with diabetes & & & & & 0.134 \\
\hline No problem & $61(32.45)$ & $36(59.02)$ & $25(40.98)$ & ref & \\
\hline Problem & $127(67.55)$ & $89(70.08)$ & $38(29.92)$ & $0.61(0.33-1.16)$ & \\
\hline Uncomfortable social situations related to diabetes & & & & & $0.002^{* *}$ \\
\hline No problem & $75(39.89)$ & $40(53.33)$ & $35(46.67)$ & ref & \\
\hline Problem & $113(60.11)$ & $85(75.22)$ & $28(24.78)$ & $0.38(0.2-0.7)$ & \\
\hline Feelings of deprivation regarding food and meals & & & & & 0.104 \\
\hline No problem & $25(13.3)$ & $13(52)$ & $12(48)$ & ref & \\
\hline Problem & $163(86.7)$ & $112(68.71)$ & $51(31.29)$ & $0.49(0.21-1.16)$ & \\
\hline Feeling depressed about thoughts of diabetes & & & & & 0.313 \\
\hline No problem & $51(27.13)$ & $31(60.78)$ & $20(39.22)$ & ref & \\
\hline Problem & $137(72.87)$ & $94(68.61)$ & $43(31.39)$ & $0.71(0.36-1.38)$ & \\
\hline Not knowing if mood is related to diabetes & & & & & $0.009^{* *}$ \\
\hline No problem & $68(36.17)$ & $37(54.41)$ & $31(45.59)$ & ref & \\
\hline Problem & $120(63.83)$ & $88(73.33)$ & $32(26.67)$ & $0.43(0.23-0.81)$ & \\
\hline Feeling overwhelmed by diabetes & & & & & 0.177 \\
\hline No problem & $40(21.28)$ & $23(57.5)$ & $17(42.5)$ & ref & \\
\hline Problem & $148(78.72)$ & $102(68.92)$ & $46(31.08)$ & $0.61(0.3-1.25)$ & \\
\hline Worrying about low sugar reactions & & & & & $0.019^{*}$ \\
\hline No problem & $57(30.32)$ & $45(78.95)$ & $12(21.05)$ & ref & \\
\hline Problem & $131(69.68)$ & $80(61.07)$ & $51(38.93)$ & $2.39(1.16-4.95)$ & \\
\hline Feeling angry about thought of living with diabetes & & & & & $0.023^{*}$ \\
\hline No problem & $60(31.91)$ & $33(55)$ & $27(45)$ & ref & \\
\hline Problem & $128(68.09)$ & $92(71.88)$ & $36(28.13)$ & $0.48(0.25-0.91)$ & \\
\hline Feeling constantly concerned about food and eating & & & & & 0.696 \\
\hline No problem & $13(6.91)$ & $8(61.54)$ & $5(38.46)$ & ref & \\
\hline Problem & $175(93.09)$ & $117(66.86)$ & $58(33.14)$ & $0.79(0.25-2.53)$ & \\
\hline Worrying about the future and complications & & & & & 0.100 \\
\hline No problem & $30(15.96)$ & $16(53.33)$ & $14(46.67)$ & ref & \\
\hline Problem & $158(84.04)$ & $109(68.99)$ & $49(31.01)$ & $0.51(0.23-1.13)$ & \\
\hline Guilty and anxious when off track management & & & & & $0.022^{*}$ \\
\hline No problem & $49(26.06)$ & $26(53.06)$ & $23(46.94)$ & ref & \\
\hline Problem & $139(73.94)$ & $99(71.22)$ & $40(28.78)$ & $0.46(0.23-0.89)$ & \\
\hline Not accepting "diabetes" & & & & & 0.085 \\
\hline No problem & $115(61.17)$ & $71(61.74)$ & $44(38.26)$ & ref & \\
\hline Problem & $73(38.83)$ & $54(73.97)$ & $19(26.03)$ & $0.57(0.3-1.08)$ & \\
\hline Feeling unsatisfied with diabetes physician & & & & & 0.089 \\
\hline No problem & $131(69.68)$ & $82(62.6)$ & $49(37.4)$ & ref & \\
\hline Problem & $57(30.32)$ & $43(75.44)$ & $14(24.56)$ & $0.54(0.27-1.1)$ & \\
\hline
\end{tabular}


TABLE 4: Continued.

\begin{tabular}{|c|c|c|c|c|c|}
\hline \multirow[t]{2}{*}{ Items } & \multirow{2}{*}{$\begin{array}{l}\text { Total } \\
n\left(\%^{\mathrm{a}}\right)\end{array}$} & \multicolumn{2}{|c|}{$\begin{array}{c}\text { Adherent (MARS-5 } \\
\text { score of 25) }\end{array}$} & \multicolumn{2}{|c|}{ Unadjusted } \\
\hline & & No, $n\left(\%^{\mathrm{b}}\right)$ & Yes, $n\left(\%^{\mathrm{b}}\right)$ & Odds ratio & $p$ value \\
\hline Diabetes taking too much of mental energy & & & & & $<0.001^{* * *}$ \\
\hline No problem & $50(26.6)$ & $21(42)$ & $29(58.00)$ & ref & \\
\hline Problem & $138(73.4)$ & $104(75.36)$ & $34(24.64)$ & $0.24(0.12-0.47)$ & \\
\hline Feeling alone with diabetes & & & & & $<0.001^{* * *}$ \\
\hline No problem & $84(44.68)$ & $44(52.38)$ & $40(47.62)$ & ref & \\
\hline Problem & $104(55.32)$ & $81(77.88)$ & $23(22.12)$ & Six & \\
\hline Friends and family not supportive & & & & & 0.497 \\
\hline No problem & $69(36.7)$ & $48(69.57)$ & $21(30.43)$ & ref & \\
\hline Problem & $119(63.3)$ & $77(64.71)$ & $42(35.29)$ & $1.25(0.66-2.35)$ & \\
\hline Coping with complications of diabetes & & & & & $<0.001^{* * *}$ \\
\hline No problem & $76(40.43)$ & $39(51.32)$ & $37(48.68)$ & ref & \\
\hline Problem & $112(59.57)$ & $86(76.79)$ & $26(23.21)$ & $0.32(0.17-0.6)$ & \\
\hline Feeling "burned out" by constant effort to manage & & & & & $0.008^{* *}$ \\
\hline No problem & $65(34.57)$ & $35(53.85)$ & $30(46.15)$ & ref & \\
\hline Problem & $123(65.43)$ & $90(73.17)$ & $33(26.83)$ & $0.43(0.23-0.8)$ & \\
\hline
\end{tabular}

$\%^{\mathrm{a}}$ : column percentage; $\%{ }^{\mathrm{b}}$ : row percentages; $n$ : number of observations; ${ }^{*} p<0.01,{ }^{* *} p<0.01$, and ${ }^{* * *} p<0.001$; CI: confidence interval; ref: reference category; LQ: lower quartile; UQ: upper quartile; $p$ values were obtained from an unadjusted binary logistic regression model.

TABLE 5: Factor loadings, communalities $\left(h^{2}\right)$, and percent of variance for principal factor extraction and varimax rotation on items of diabetes distress.

\begin{tabular}{|c|c|c|c|c|c|}
\hline Items & ${ }^{\mathrm{a}} F_{1}$ & $F_{2}$ & $F_{3}$ & $F_{4}$ & $h^{2}$ \\
\hline \multicolumn{6}{|l|}{ Negative emotions about diabetes } \\
\hline Feeling discouraged with diabetes treatment plan & 0.472 & & & & 0.344 \\
\hline Scared about thoughts of living with diabetes & 0.643 & & & & 0.604 \\
\hline Uncomfortable social situations related to diabetes & 0.640 & & & & 0.495 \\
\hline Feeling depressed about thoughts of diabetes & 0.708 & & & & 0.689 \\
\hline Not knowing if mood is related to diabetes & 0.709 & & & & 0.597 \\
\hline Feeling overwhelmed by diabetes & 0.466 & & & & 0.494 \\
\hline Feeling angry about thought of living with diabetes & 0.606 & & & & 0.656 \\
\hline Worrying about the future and complications & 0.610 & & & & 0.519 \\
\hline Guilty and anxious when off-track management & 0.603 & & & & 0.435 \\
\hline Diabetes taking too much of mental energy & 0.540 & & & & 0.500 \\
\hline Feeling alone with diabetes & 0.570 & & & & 0.528 \\
\hline Coping with complications of diabetes & 0.603 & & & & 0.712 \\
\hline Feeling burned out & 0.611 & & & & 0.641 \\
\hline \multicolumn{6}{|l|}{ Dietary concerns and diabetes care } \\
\hline No clear or concrete goals for diabetes care & & 0.529 & & & 0.711 \\
\hline Feelings of deprivation regarding food and meals & & 0.596 & & & 0.600 \\
\hline \multicolumn{6}{|l|}{ Dissatisfaction with external support } \\
\hline Feeling unsatisfied with diabetes physician & & & 0.464 & & 0.736 \\
\hline Friends and family not supportive & & & 0.596 & & 0.627 \\
\hline \multicolumn{6}{|l|}{ Diabetes management helplessness } \\
\hline Coping with complications of diabetes & & & & 0.510 & 0.712 \\
\hline Feeling burned out by constant effort to manage diabetes & & & & 0.489 & 0.641 \\
\hline Percent variance & 27.179 & 7.485 & 6.906 & 6.427 & \\
\hline
\end{tabular}

${ }^{a}$ Factor labels: $F_{1}$ : negative emotions about diabetes; $F_{2}$ : dietary concerns and diabetes care; $F_{3}$ : dissatisfaction with external support; $F_{4}$ : diabetes management helplessness. 
regardless of evidence that psychosocial support is helpful in adaptive behaviours by patients with T2DM [49]. Support and care from the social networks of patients including health care professionals, family, friends, neighbours, colleagues, and fellow patients with T2DM could help them take positive stances, build resilience, relieve distress, and improve on their well-being [50, 51]. Furthermore, care and support from for$\mathrm{mal}$ and familial contacts have positive effects on the medication adherence behaviour in patients with T2DM due to the encouragement of optimism in such patients [52].

The prevalence of both chronic microvascular and acute complications of T2DM is much greater in patients with poor glycemic control and poor dietary quality [10, 53, 54]. Concerns about meeting dietary requirements and following treatment plans were also synonymous to the concept of diabetes distress in this study. Psychological distress has been associated with a high risk of T2DM complications, and in this study, patients who had difficulty dealing with their complications reported poor medication adherence behaviour. The occurrence of diabetic complications has been proposed to be significantly higher in nonadherent patients compared to those who adhere to medications [53].

As indicated in Introduction, patients with high diabetesrelated distress show signs of poor self-management of T2DM [21], and in this study, high blood glucose levels and distress were significantly related. Similar to previous studies, this study suggests that assessment and management of distress in patients with T2DM are crucial in determining health outcomes. It was observed that participants who felt highly distressed by the constant effort needed to manage T2DM poorly adhered to their medications $[55,56]$.

This study has some limitations. First, a mixed method design could have been adopted for this study in order to explore the concept of diabetes distress from a more qualitative approach. Second, respondents are from only one hospital; thus, the findings may not be representative of the general population patients with T2DM in Ghana; in addition, causality could not be established nor could the direction of the effect of diabetes distress on adherence be determined because the data were obtained through a cross-sectional study approach. Given that this study relied on self-reports, recall bias could be a limitation. In spite of these limitations, this study is among the first to report the association between T2DM distress and nonadherence in Ghana, thus identifying areas of context-specific interventions to improve adherence in patients with T2DM.

4.1. Implications for Clinical Practice. These study findings are significant in explaining the association between psychosocial interactions and health outcomes in patients with T2DM. Based on the results, psychological and social context-specific interventions that address diabetes distress should be considered when patients with diabetes are managed at health institutions. For example, culturally relevant communications may need to be developed, pilot-tested, and implemented to address psychological issues confronting patients with T2DM in Ghana. Other cultural dimensions that impact treatment outcomes such as religiosity could also be explored in the management of T2DM in Ghana.
4.2. Implications for Policy. It may also be relevant to recommend that routine screening for diabetes distress be incorporated into national standard diabetes treatment guidelines for care within the health care systems in Ghana. This is to ensure that patients with a possible risk of distress can receive more comprehensive diabetic care from a psychosocial perspective.

\section{Conclusion}

This study investigated the link between diabetes distress and medication adherence in patients with T2DM in Ghana. The information suggests that diabetes distress is a significant determinant of medication adherence behaviour. Thus, incorporating routine screening for distress into the standard diabetes care within the Ghanaian health system and having health practitioners adopt a biopsychosocial approach to diabetes management will be important context-specific interventions to improve health outcomes of people living and coping with T2DM.

\section{Data Availability}

The data that support the findings of this study are available from the corresponding author, [IAK], upon reasonable request.

\section{Conflicts of Interest}

All authors have no conflict of interest to declare.

\section{Acknowledgments}

The authors would like to acknowledge the staff and patients at the Pantang Hospital for their support in this study and during the data collection process. Appreciation also goes to the following for their various roles in the preparation of this paper: Prof. Yaa Ntiamoah Badu and the BANGAAfrica writeshop team, Dr. Rabui Asante, and Mr. Kofi Adjabeng.

\section{References}

[1] L. Nalysnyk, M. Hernandez-Medina, and G. Krishnarajah, "Glycaemic variability and complications in patients with diabetes mellitus: evidence from a systematic review of the literature," Diabetes, Obesity and Metabolism, vol. 12, no. 4, pp. 288-298, 2010.

[2] J. Bhutani and S. Bhutani, "Worldwide burden of diabetes," Indian Journal of Endocrinology and Metabolism, vol. 18, no. 6, pp. 868-870, 2014.

[3] T. Psaltopoulou, I. Ilias, and M. Alevizaki, "The role of diet and lifestyle in primary, secondary, and tertiary diabetes prevention: a review of meta-analyses," The Review of Diabetic Studies, vol. 7, no. 1, pp. 26-35, 2010.

[4] C. Zhang and Y. Ning, "Effect of dietary and lifestyle factors on the risk of gestational diabetes: review of epidemiologic evidence," The American Journal of Clinical Nutrition, vol. 94, suppl_6,pp. 1975S-1979S, 2011. 
[5] K. Ogurtsova, J. D. da Rocha Fernandes, Y. Huang et al., "IDF Diabetes Atlas: global estimates for the prevalence of diabetes for 2015 and 2040," Diabetes Research and Clinical Practice, vol. 128, pp. 40-50, 2017.

[6] M. Asamoah-Boaheng, O. Sarfo-Kantanka, A. B. Tuffour, B. Eghan, and J. C. Mbanya, "Prevalence and risk factors for diabetes mellitus among adults in Ghana: a systematic review and meta-analysis," International Health, vol. 11, no. 2, pp. 83-92, 2018.

[7] S. T. Miller and T. A. Elasy, "Psychometric evaluation of the Problem Areas in Diabetes (PAID) survey in southern, rural African American women with type 2 diabetes," BMC Public Health, vol. 8, no. 1, 2008.

[8] A. U. Pandit, S. C. Bailey, L. M. Curtis et al., "Disease-related distress, self-care and clinical outcomes among low-income patients with diabetes," Journal of Epidemiology and Community Health, vol. 68, no. 6, pp. 557-564, 2014.

[9] R. R. Rubin, "Adherence to pharmacologic therapy in patients with type 2 diabetes mellitus," The American Journal of Medicine, vol. 118, no. 5, pp. 27-34, 2005.

[10] J. Silverman, J. Krieger, M. Kiefer, P. Hebert, J. Robinson, and K. Nelson, "The relationship between food insecurity and depression, diabetes distress and medication adherence among low-income patients with poorly-controlled diabetes," Journal of General Internal Medicine, vol. 30, no. 10, pp. 1476-1480, 2015.

[11] J. Aikens and J. Piette, "Longitudinal association between medication adherence and glycaemic control in type 2 diabetes," Diabetic Medicine, vol. 30, no. 3, pp. 338-344, 2013.

[12] K. M. P. Van Bastelaar, F. Pouwer, P. H. L. M. Geelhoed-Duijvestijn et al., "Diabetes-specific emotional distress mediates the association between depressive symptoms and glycaemic control in type 1 and type 2 diabetes," Diabetic Medicine, vol. 27, no. 7, pp. 798-803, 2010.

[13] L. Fisher, J. T. Mullan, P. Arean, R. E. Glasgow, D. Hessler, and U. Masharani, "Diabetes distress but not clinical depression or depressive symptoms is associated with glycemic control in both cross-sectional and longitudinal analyses," Diabetes Care, vol. 33, no. 1, pp. 23-28, 2010.

[14] L. Fisher, J. Gonzalez, and W. Polonsky, "The confusing tale of depression and distress in patients with diabetes: a call for greater clarity and precision," Diabetic Medicine, vol. 31, no. 7, pp. 764-772, 2014.

[15] L. Fisher, W. H. Polonsky, D. M. Hessler et al., "Understanding the sources of diabetes distress in adults with type 1 diabetes," Journal of Diabetes and its Complications, vol. 29, no. 4, pp. 572-577, 2015.

[16] L. M. Delahanty, R. W. Grant, E. Wittenberg et al., “Association of diabetes-related emotional distress with diabetes treatment in primary care patients with type 2 diabetes," Diabetic Medicine, vol. 24, no. 1, pp. 48-54, 2007.

[17] R. N. Baek, M. L. Tanenbaum, and J. S. Gonzalez, "Diabetes burden and diabetes distress: the buffering effect of social support," Annals of Behavioral Medicine, vol. 48, no. 2, pp. 145155, 2014.

[18] B. Karlsen, B. Oftedal, and E. Bru, "The relationship between clinical indicators, coping styles, perceived support and diabetes-related distress among adults with type 2 diabetes," Journal of Advanced Nursing, vol. 68, no. 2, pp. 391-401, 2012.

[19] J. Schabert, J. L. Browne, K. Mosely, and J. Speight, "Social stigma in diabetes : a framework to understand a growing problem for an increasing epidemic," The Patient-PatientCentered Outcomes Research, vol. 6, no. 1, pp. 1-10, 2013.

[20] N. S. Levitt, "Diabetes in Africa: epidemiology, management and healthcare challenges," Heart, vol. 94, no. 11, pp. 13761382, 2008.

[21] C. Fritschi and L. Quinn, "Fatigue in patients with diabetes: a review," Journal of Psychosomatic Research, vol. 69, no. 1, pp. 33-41, 2010.

[22] W. Polonsky, Diabetes Burnout: What to Do When You Can't Take It Anymore, American Diabetes Association, 1999.

[23] A. K. Symon, S. S. Vargese, E. Mathew, K. R. Akshay, and J. Abraham, "Diabetes related distress in adults with type 2 diabetes mellitus: a community-based study," International Journal Of Community Medicine And Public Health, vol. 6, no. 1, pp. 151-155, 2018.

[24] A. J. Sommerfield, I. J. Deary, and B. M. Frier, “Acute hyperglycemia alters mood state and impairs cognitive performance in people with type 2 diabetes," Diabetes Care, vol. 27, no. 10, pp. 2335-2340, 2004.

[25] V. Stephani, D. Opoku, and D. Beran, "Self-management of diabetes in sub-Saharan Africa: a systematic review," BMC Public Health, vol. 18, no. 1, p. 1148, 2018.

[26] A. D.-G. Aikins, "Ghana's neglected chronic disease epidemic: a developmental challenge," Ghana Medical Journal, vol. 41, no. 4, pp. 154-159, 2007.

[27] W. Bosu, "A comprehensive review of the policy and programmatic response to chronic non-communicable disease in Ghana," Ghana Medical Journal, vol. 46, no. 2, pp. 69-78, 2012.

[28] A. D.-G. Aikins, "Living with diabetes in rural and urban Ghana: a critical social psychological examination of illness action and scope for intervention," Journal of Health Psychology, vol. 8, no. 5, pp. 557-572, 2003.

[29] A. D.-G. Aikins, "Strengthening quality and continuity of diabetes care in rural Ghana: a critical social psychological approach," Journal of Health Psychology, vol. 9, no. 2, pp. 295-309, 2004.

[30] A. G. Amoah, S. K. Owusu, and S. Adjei, "Diabetes in Ghana: a community based prevalence study in Greater Accra," Diabetes Research and Clinical Practice, vol. 56, no. 3, pp. 197-205, 2002.

[31] M. Cook-Huynh, D. Ansong, R. C. Steckelberg et al., "Prevalence of hypertension and diabetes mellitus in adults from a rural community in Ghana," Ethnicity \& Disease, vol. 22, no. 3, pp. 347-352, 2012.

[32] I. Danquah, G. Bedu-Addo, K. J. Terpe et al., "Diabetes mellitus type 2 in urban Ghana: characteristics and associated factors," BMC Public Health, vol. 12, no. 1, 2012.

[33] L. K. Frank, J. Kröger, M. B. Schulze, G. Bedu-Addo, F. P. Mockenhaupt, and I. Danquah, "Dietary patterns in urban Ghana and risk of type 2 diabetes," British Journal of Nutrition, vol. 112, no. 1, pp. 89-98, 2014.

[34] S. M. Gatimu, B. W. Milimo, and M. S. Sebastian, "Prevalence and determinants of diabetes among older adults in Ghana," BMC Public Health, vol. 16, no. 1, p. 1174, 2016.

[35] S. P. Bruce, F. Acheampong, and I. Kretchy, "Adherence to oral anti-diabetic drugs among patients attending a Ghanaian teaching hospital," Pharmacy Practice, vol. 13, no. 1, p. 533, 2015.

[36] V. Mogre, Z. O. Abanga, F. Tzelepis, N. A. Johnson, and C. Paul, "Adherence to and factors associated with self-care 
behaviours in type 2 diabetes patients in Ghana," BMC Endocrine Disorders, vol. 17, no. 1, p. 20, 2017.

[37] G. W. Welch, A. M. Jacobson, and W. H. Polonsky, "The Problem Areas in Diabetes Scale: an evaluation of its clinical utility," Diabetes Care, vol. 20, no. 5, pp. 760-766, 1997.

[38] R. Horne and J. Weinman, "Patients' beliefs about prescribed medicines and their role in adherence to treatment in chronic physical illness," Journal of Psychosomatic Research, vol. 47, no. 6, pp. 555-567, 1999.

[39] C. S. Lee, J. H. M. Tan, U. Sankari, Y. L. E. Koh, and N. C. Tan, "Assessing oral medication adherence among patients with type 2 diabetes mellitus treated with polytherapy in a developed Asian community: a cross-sectional study," BMJ Open, vol. 7, no. 9, 2017.

[40] W. H. Polonsky, B. J. Anderson, P. A. Lohrer et al., "Assessment of diabetes-related distress," Diabetes Care, vol. 18, no. 6, pp. 754-760, 1995.

[41] S. S. Jaser, N. Patel, R. L. Rothman, L. Choi, and R. Whittemore, "Check it! A randomized pilot of a positive psychology intervention to improve adherence in adolescents with type 1 diabetes," The Diabetes Educator, vol. 40, no. 5, pp. 659-667, 2014.

[42] W. H. Polonsky, L. Fisher, J. Earles et al., "Assessing psychosocial distress in diabetes: development of the diabetes distress scale," Diabetes Care, vol. 28, no. 3, pp. 626-631, 2005.

[43] A. B. Grigsby, R. J. Anderson, K. E. Freedland, R. E. Clouse, and P. J. Lustman, "Prevalence of anxiety in adults with diabetes: a systematic review," Journal of Psychosomatic Research, vol. 53, no. 6, pp. 1053-1060, 2002.

[44] R. J. Anderson, K. E. Freedland, R. E. Clouse, and P. J. Lustman, "The prevalence of comorbid depression in adults with diabetes: a meta-analysis," Diabetes Care, vol. 24, no. 6, pp. 1069-1078, 2001.

[45] G. E. Simon and M. Von Korff, "Medical co-morbidity and validity of DSM-IV depression criteria," Psychological Medicine, vol. 36, no. 1, pp. 27-36, 2006.

[46] M. M. Skaff, J. T. Mullan, D. M. Almeida et al., "Daily negative mood affects fasting glucose in type 2 diabetes," Health Psychology, vol. 28, no. 3, pp. 265-272, 2009.

[47] T. W. Smith, "Personality as risk and resilience in physical health," Current Directions in Psychological Science, vol. 15, no. 5, pp. 227-231, 2006.

[48] S. M. Robertson, M. A. Stanley, J. A. Cully, and A. D. Naik, "Positive emotional health and diabetes care: concepts, measurement, and clinical implications," Psychosomatics, vol. 53, no. 1, pp. 1-12, 2012.

[49] S. Mohebi, M. Parham, G. Sharifirad, Z. Gharlipour, A. Mohammadbeigi, and F. Rajati, "Relationship between perceived social support and self-care behavior in type 2 diabetics: a cross-sectional study," Journal of Education and Health Promotion, vol. 7, no. 1, p. 48, 2018.

[50] G. Spencer-Bonilla, O. J. Ponce, R. Rodriguez-Gutierrez et al., "A systematic review and meta-analysis of trials of social network interventions in type 2 diabetes," BMJ Open, vol. 7, no. $8,2017$.

[51] J. L. Strom and L. E. Egede, "The impact of social support on outcomes in adult patients with type 2 diabetes: a systematic review," Current Diabetes Reports, vol. 12, no. 6, pp. 769781, 2012.

[52] L. Gu, S. Wu, S. Zhao et al., "Association of social support and medication adherence in Chinese patients with type 2 diabetes mellitus," International Journal of Environmental Research and Public Health, vol. 14, no. 12, p. 1522, 2017.

[53] T. B. Gibson, X. Song, B. Alemayehu et al., "Cost sharing, adherence, and health outcomes in patients with diabetes," The American Journal of Managed Care, vol. 16, no. 8, pp. 589-600, 2010.

[54] F. S. Marinho, C. B. M. Moram, P. C. Rodrigues, N. C. Leite, G. F. Salles, and C. R. L. Cardoso, "Treatment adherence and its associated factors in patients with type 2 diabetes: results from the Rio de Janeiro type 2 diabetes cohort study," Journal of Diabetes Research, vol. 2018, Article ID 8970196, 8 pages, 2018.

[55] N. Kumar, B. Unnikrishnan, R. Thapar et al., "Distress and its effect on adherence to antidiabetic medications among type 2 diabetes patients in Coastal South India," Journal of Natural Science, Biology, and Medicine, vol. 8, no. 2, p. 216, 2017.

[56] L. A. Nelson, K. A. Wallston, S. Kripalani, L. M. LeStourgeon, S. E. Williamson, and L. S. Mayberry, "Assessing barriers to diabetes medication adherence using the informationmotivation-behavioral skills model," Diabetes Research and Clinical Practice, vol. 142, pp. 374-384, 2018. 